\title{
GANDAVO E OS CLÁSSICOS: ENTRE MIMESE E IMITATIO
}

\author{
MARCUS BACAMARTE \\ Universidade Federal de Viçosa (UFV)
}

\begin{abstract}
Resumo: Este artigo apresenta uma relação entre a crónica dos descobrimen os no século XVI, e a traduçăo clássica, a partir da obra de Pero de Magalháes Gandavo. Seguindo o percurso da mimese, na cultura grega, e sua posterior reduçáo a imitatio a partir da cultura romana e especialmente no século XVI, procura-se apreender as relaçōes entre história e fiç̧ão e o papel do desejo como intérprete na compreensáo européia da América.
\end{abstract}

Palavras-chave: Imitatio - historia - ficção-descobrimentos.

Desde Voltaire, a tradição critica vem atribuindo aos séculos $X V$ e $X V I$, sob a palavra mágica Renascimento, uma atitude de retomada do pensamento clássico. Tal atitude, compreendida como superação racionalista de uma mentalidade arcaica, categorizava duas regiōes de luz e sombra absolutas: a Idade Média como a treva a ser banida e a Antigüidade como a claridade a ser recuperada.

Essa projeção que, desde o iluminismo até hoje, se faz sobre os séculos XV e XVI, nunca levou muito em consideração a complexidade mental desse momento histórico, nem tampouco da cultura antiga.

A construçăo da história é sempre dependente do olhar que, do presente, se lança sobre o passado. E o desejo de razão da ldade Moderna é o que comandou sempre a apreensão do "Renascimento", como da cultura clássica.

As crônicas dos descobrimentos, textos que se encontram no centro da problemática do século XVI, corporificam aquela atitude, assim como mostram o seu reverso. $\mathrm{Na}$ busca naturalista da apreensão de uma verdade objetiva da realidade americana, os cronistas deixam-se trair por sua ardilosa construção textual, e se enredam nas malhas do discurso justamente quando tentam controlar a imaginação e submetê-la a uma razăo imitativa, que tenta fazer transparecer na linguagem a paisagem do mundo, sem considerar a opacidade de todo discurso.

Autores como Caminha, Hernando Colón, Hans Staden, Jean de Lery ou Fernão Cardim têm como demarcação discursiva a busca incessante de um estatuto de verdade em seus textos. Os narradores das crônicas insistem na sua condiçăo de testemunha ocular assim como num recurso à autoridade dos antigos para garantir ao leitor a verossimilhança do narrado.

Vejamos um exemplo de Pero de Magalhăes Gandavo, retirado do "prólogo do leitor" da História da Provfncia de Santa Cruz, o primeiro texto sobre o Brasil que se auto-intitula história. Segundo o autor, há na nova terra coisas tão notáveis e dignas de admiraçăo que

"parece̊ra descuido e pouca curiosidade nossa, nam fazer mençam delas em allgum discurso, e da-las à perpetua memória, como costumavão os antigos: aos quaes nam escapava cousa alguma que por extenso năo reduzissem a história, e fizessem mençam em suas escrituras de cousas menores que estas, as quaes hoje em dia vivem entre nós 
como sabemos, e viverāo eternamente. $E$ se os antigos portuguezes, e ainda os modernos nam foram tam pouco affeiçoados à escritura como sam, nam se perderão tantas antiguidades entre nós, de que agora carecemos, nem houvera tam profundo esquecimento de muitas cousas, em cujo estudo têm muitos homens doutos cansado, e revolvido grande cópia de livros, sem as poderem descobrir nem recuperar da maneira que passárāo. Daqui vinha aos Gregos e Romanos haverem todas as outras nações por barbaras, e na verdade com razão lhes podiam dar este nome, pois erão tam pouco solicitos, e cubiçosos de honra que por sua mesma culpa deixavão morrer aquellas coisas que thes podião dar nome, e faze-los inmortaes. Como pois a escritura seja vida da memoria, e a memoria huma semelhança da inmortalidade a que todos devemos aspirar, pela parte que della nos cabe, quiz movido destas razões, fazer esta breve história, para cujo ornamento nam busquei epitetos exquisitos, nem outra formosura de vocábulos de que os eloquentes Oradores costumão usar para com artificio da palavras engrandecerem suas obras" (Gandavo, 1980, p. 76-77).

Ao lado da recusa à oratória, associando verdade e clareza de estilo, Gandavo propõe o valor social da história: saber a verdade do passado não só esclarece o presente como demarca o espaço civilizacional entre cultura e barbárie. A afeição à "escritura", enquanto guardiã da memória, torna os homens imortais, pois a memória é a semelhança da imortalidade. Gandavo atribui à prática da mimese um valor de transcendência a escrita como vida da memória. O recurso aos clássicos busca estabelecer uma linha de continuidade. Os Gregos e Romanos mimetizaram (imitaram) a imortalidade através de seus textos, logo, para nāo ser bárbaro, há que se trilhar o mesmo caminho. Buscar a verdade do passado, e do presente, vinculando escrita e imitação, garante uma existência cultural. Nessa pråtica mimética, construlda como espelho, é que se dará a representação social na qual o sujeito se vê, e a partir da qual ele moldura o mundo. Essa concepção tradicional da mimese, que traduz o conceito grego por imitatio, constitui um "erro" de implicaçōes amplas na epistemologia do século XVI. A compreensāo da mimese como imitação, conforme o texto de Gandavo, não é grega, mas uma interpretação posterior que, mais ou menos inconscientemente, perdeu o significado grego do termo.

No entanto, Gandavo toma os clássicos como auctoritas do seu argumento. A busca de naturalizar o dito se fundamenta nessa projeção de um passado mitificado sobre o presente contraditório dos descobrimentos. A questão civilizacional se coloca porque Gandavo e sua cultura estão diante de uma alteridade radical, o Novo Mundo. Falar desse espaço desconhecido, controlando suas diferenças e assimilando-as à sua propriedade, leva o cronista a construir o seu texto a partir da lógica da semelhança. Imitar, no "Renascimento", constitui uma categoria gnoseológica: imitam-se os clássicos, imita-se a natureza, imita-se a obra e a palavra de Deus. Mas como toda linguagem é opaca, como a palavra nunca diz totalmente a coisa, o discurso se torna metáfora, e a crônica se move por uma estrutura ficcional. Este é o paradoxo central da crônica dos descobrimentos: um arcabouço retórico que tenta transfomar o notado em simples anotado, que lineariza a relação entre o visto e o narrado, mas onde, no entanto, 0 desejo se insinua como intérprete.

Para entendermos como o recurso à auctoritas, relativo ao conceito de mimese, se volta contra o próprio cronista, faz-se fundamental acompanhar um pouco este conceito desde a cultura clássica.

Como deverbal de mímeisthai, a palavra mimese se liga inicialmente as práticas de encenação iniciáticas dos cultos dionisiacos, dos cultos de Ártemis e da Gorgó, entidades ligadas a todas as manifestações da alteridade na vida humana: Dioniso com o teatro, a loucura, a embriaguez, o transe, o delírio, a mascarada, o disfarce; Ártemis, a deusa das margens, dos locais onde a àgua se mistura à terra, governa a passagem da cultura à barbárie, e vice-versa, da adolescência à idade adulta (cabe lembrar que o termo concretizador da função iniciática, agogé-transporte, condução - tem a mesma raiz que explica a instrução civica, o instrutor: agogós. A função de Ártemis, portanto, se manifesta no controle, na mediação e na recondução 
da alteridade); A Górgona Medusa é a própria máscara da diferença, do absolutamente Outro, que se contemplado se apossa do humano de tal forma que este com ele se identifica, transformando-se em pedra.

O estrangeiro, a margem ou a mortę: a diferença sempre vista pela máscara, pela mimese, porque essas experiências do limite jamais podem aparecer claramente aos nossos olhos, sob o risco de virarmos pedra ou ficarmos cegos pelo brilho epifânico do deus. A alteridade se esconde sob a sua própria revelação, pois vem disfarçada, dissimulada. Dessa maneira se explica o fato de Penteu, nas Bacantes (Eurípedes, 1983, p. 255), não reconhecer Dioniso no estrangeiro que o convida a ver o culto dionisiaco nas montanhas. A maquilagem, os gestos, as roupas compõe uma persona que mostra tanto quanto dissimula. Em todo esse contexto, mimeisthai jamais significa imitar, e sim mascarar, representar, ficcionalizar.

Platão, no comentado passo da expulsão do poeta de sua cidade ideal (Platão, 1983, p. 472), se opõe à poesia não por sua inutilidade (como às vezes tem sido apressadamente lido), mas exatamente porque reconhece a enorme capacidade da poesia de influenciar as pessoas. O fato de a poesia estar afastada da essência da verdade é o que motiva sua condenaçāo, que se explica por um motivo ainda mais forte:

"Não é essa a maior acusação que fazemos à poesia: mas o dano que ela pode causar até às pessoas honestas, com excessão de um escassissimo número, isto é que é o grande perigo" (Platảo, 1983 p. 472).

Há em Platão um projeto político. Sua condenação da poesia faz, na verdade, o seu elogio, ainda que às avessas. O imitador (mimetés), esse "criador de fantasmas" (Idem, 1983, p. 464), pode ser reconduzido à cidade de sua imitação se restringir a cantar "hinos aos deuses" (Idem, p. 475). O mimetés é perigoso exatamente por ser criador, por não se ater a imitar o real. Há em Platão uma distinção entre o "imitador da realidade", o artffice (demiourgós) e o "imitador da aparência" (mimetés) (Idem, p. 457). Ambos se distinguem da divindade (phytourgós), verdadeira criadora da natureza. $O$ imitador da aparência está, no entanto, muito afastado da divindade e este fato marca sua prática, como comenta Emilio Lledó Iñigo: "esta distancia de la idea originaria es lo que define al mimetés" (Iñigo, 1983 p. 100). Não importa então na mimese a produção de uma realidade conforme outra. Ela não se define por uma relação de dependência entre entes ou realidades, mas exatamente ao contrário. Por isso Platão a condena. O critério platônico se baseia puramente no funcional. Do ponto de vista de uma definição do produto mimético não há distinção fundamental em relação a um sofista como Górgias, com sua distinção entre engano e erro. Esse fato só vem na verdade reafirmar que a leitura da obra de Platão tem desconhecido o fato de ser ele também um criador de argumentos, um poeta, um filósofo que recorre ao mito como estrutura argumentativa e, sobretudo, faz filosofia a partir das palavras. A idéia do simulacro como potência criadora já está no poeta Platão.

Quanto a Aristóteles, nada mais enganoso do que atribuir-lhe uma concepção "realista" de mimese. A noção de uma cópia servil da realidade, da natureza ou das açōes dos homens não está de forma alguma na exposição aristotélica da mimese: "... é evidente que não compete ao poeta narrar exatamente o que aconteceu, mas sim o que poderia ter acontecido..." (Aristóteles, s/d, p. 312).

Esse breve roteiro mostra que o conceito de mimese liga-se a muitas outras práticas além da imitação. Nos rituais dionislacos a mimese expressa a idéia de possessão, de encenação da alteridade, que se desdobra no presentar do teatro ou na sedução da palavra persuasiva. Platāo entende mimese e mimetés como criadores. Aristóteles reconhece sua autonomia, seu caráter de potência que demanda reatualização.

A cultura latina, traduzindo o conceito grego por imitativo, irá se prender ao aspecto formal da análise aristotélica. Mimese se reduz ao metro e ao ritmo do poema. Esse fato associado à noçăo aristotélica de phýsis como limite de todas as coisas, vai possibilitar ao pensamento dos séculos XV e XVI, e dal em diante, a restrição do conceito a simples imitação. Lendo a 
mimese como imitatio, esse pensamento trabalhou para limitar o alcance do conceito grego, sob o pretexto de reiterar a lição de Aristóteles. Tal procedimento se deveu a condições socioreligiosas especfficas, como forma de combater o ressurgimento da subjetividade que, a partir do século XII, ameaça subverter a ordem cósmica ${ }^{1}$. E que se amplie no século XVI como elemento de controle e ordenamento da alteridade revelada nos descobrimentos.

Dessa forma, Gandavo, como todos os outros cronistas dos descobrimentos, ao buscar a autoridade dos antigos como forma de garantir sua lógica naturalista, faz exatemente o inverso e reafirma a potência ficcional da mimese.

Como exemplo desse fato, podemos ver uma descrição que Gandavo faz do tatu:

"Chamão-Ihe tatüs, são tamanhos como coelhos e tem hum casco à maneira de lagosta como de cagado, mas he repartido em muitas juntas como laminas; parecem totalmente um cavallo armado, têm um rabo do mesmo casco comprido, o focinho é como de leitão, e não botam mais fora do casco que a cabeça, têm as pernas baixas e criam-se em covas, a carne delles tem o sabor quase como de galinha" (Gandavo, 1980, p. 49).

As comparações caminham em tantas direçōes que aquilo que deveria explicar termina com um absurdo poético. Um ser imaginário, um monstro pré-diluviano, digno de uma enciclópédia borgiana se revela ao final da descrição, que se queria "realista". Só há um lugar capaz de comportar enumeração tão absurda: a linguagem. $O$ tatu constitui um ser da linguagem e para a linguagem. Tem o tamanho de um coelho, mas parece um cavalo (o adjetivo armado remete esse cavalo, por exemplo, aos das cruzadas com as suas armaduras); cria-se em covas, mas é como uma lagosta ou cágado; tem rabo comprido, mas focinho de leitão; e, pairando sobre todas as outras observaçōes, tem sabor de galinha: o tatu voa, mora na água salgada ou na doce, mora no fundo da terra; é roedor, crustáceo, mamifero e oviparo; atravessa o tempo, a história, a geografia e a literatura para ficar pairando nesse lugar do possível, a linguagem. Tem al o seu habitat de animal compósito, significante para onde acorrem todos os significados possiveis. Enquanto resultado de tantos seres e conceitos, o tatu condensa uma grande metáfora da América. Apresentando-o ao olhar europeu, Gandavo diz de uma só vez todos os possíveis e impossiveis, tanto do Novo Mundo quanto do desejo da Europa colocado sobre ele. E ao dizê-lo, buscando a autoridade dos clássicos e caindo na armadilha da mimese, Gandavo deixa ver as intricadas relaçōes entre história e ficção, possibilitando que vejamos o quanto o discurso historiográfico se alimenta da fiç̧ão, pois, como linguagem, a história é metáfora, e nunca fato transparente.

\section{Résumé:}

Ce travail analyse les relations entre la mimesis et la imitatio dans le discour sur la découverte de l'Amerique en rapport avec la culture classique, a partir de l'oeuvre de Pero de Magalhães Gandavo.

1. Para uma visăo detalhada cf. COSTA LIMA, Luiz. O Controle do Imaginário. Săo Paulo, Brasillense, 1984, cap. I; LE GOFF, Jacques. O maravilhoso o o Quotidiano no Ocidente Medieval. Lisboa, 70, 1985. e ainda FREITAS, Marcus Vinicius de (Marcus Bacamarte). A Descoberta da Ficgăo: a crónica e o Brasil no século XVI. Belo Horizonte, FALE/UFMG, 1990 (dissertaçăo de mestrado). 


\section{REFERÊNCIAS BIBLIOGRÁFICAS}

ARISTÓTELES. Arte Poética. São Paulo: Ediouro, s/d.

COSTA LIMA, Luiz. O Controle do Imaginário. São Paulo: Brasiliense, 1984, cap. I.

EURIPEDES. Alceste - Andrómaca - lon - As Bacantes. Lisboa / São Paulo: Verbo, 1973.

FREITAS, Marcus Vinicius de (Marcus Bacamarte). A Descoberta da Fiç̧ão: a crônica e o Brasil no século XVI. Belo Horizonte: Curso de Pós-Graduçaō em Letras, FALE/UFMG, 1990 (dissertação de mestrado).

GANDAVO, Pero de Magalhães. Tratado da Terra do Brasil - Historia da Provincia de Santa Cruz. Belo Horizonte: Itatiaia, 1980.

INIIGO, Emilio Lledó. El Concepto "Poiesis" en La Filosofia Griega. Madrid: Consejo Superior de Insvestigaciones Cientificas, 1961.

LE GOFF, Jacques. O Maravilhoso e o Quotidiano no Ocidente Medieval. Lisboa: Ediçōes 70, 1985.

PLATÃo. República. Trad. Maria Helena da Rocha Pereira. Lisboa: Calouste GulbenKian, 1983. 